\title{
A Case Report of Primary Breast Angiosarcoma: Clinical Presentation and Outcome After Adjuvant Radiotherapy
}

\author{
Özgür Altmışdörtoğlu ${ }^{1}$ (), Mustafa Şehsuvar Gökgöz ${ }^{2}$ (D), Ulviye Yalçınkaya ${ }^{3}$ (), Meltem Nalca Andrieu ${ }^{1}$ \\ ${ }^{1}$ Department of Radiation Oncology, Near East University School of Medicine, Nicosia, Turkish Republic of Northern Cyprus \\ ${ }^{2}$ Department of General Surgery, Uludağ University School of Medicine, Bursa, Turkey \\ ${ }^{3}$ Department of Pathology, Uludağ University School of Medicine, Bursa, Turkey
}

\begin{abstract}
Angiosarcomas of the breast are infrequent subtypes of sarcoma that are often diagnosed after radiation therapy for primary breast cancer. Primary angiosarcomas (PAS) are rare tumors that constitute $0.04 \%$ of all malignant breast tumors. We report a case of a 40 -year-old woman with a lump in the right breast and diagnosed as angiosarcoma by pathological evaluation. She underwent simple mastectomy followed by adjuvant radiation. She is alive and disease-free for 66 months although tumor size was large and one surgical margin was tumor positive. Breast angiosarcoma is often in advanced stage at diagnosis and tends to recur locally. Although surgical methods constitute the primary treatment, we believe that a multidisciplinary treatment strategy should be used in high-risk patients with large primary tumors and tumor positive margins.
\end{abstract}

Keywords: Breast, primary angiosarcoma, radiotherapy, surgery

Cite this articles as: Altmışdörtoğlu Ö, Gökgöz MŞ, Yalçınkaya U, Nalca Andrieu M. A Case Report of Primary Breast Angiosarcoma: Clinical Presentation and Outcome After Adjuvant Radiotherapy. Eur J Breast Health 2020; 16(4): 290-294.

\section{Introduction}

Angiosarcoma (AS) is an aggressive tumor with differentiation to the endothelium of blood or lymphatic vessels. The tumor may arise from connective tissues in any anatomical region, including the scalp, the breast and the extremities and may spread over the overlying skin (1). They compose $1 \%$ of all sarcomas and the frequency is $0.0005-0.05 \%$ of all malignant neoplasms of the breast (2). Breast angiosarcomas may be classified as primary or secondary angiosarcoma, Primary angiosarcoma is a first-time developing tumor, while secondary angiosarcoma develops as a result of former breast cancer treatment (e.g., used postoperative radiotherapy and/or long-lasting lymphedema after treatment for breast cancer known as Stewart-Treves syndrome) (3). As primary angiosarcoma of the breast (PAB) is an uncommon malignancy, there are no randomized trials to lead clinical decision-making in the management of angiosarcoma.

\section{Case Presentation}

A 40-year-old premenopausal patient who had a breast reduction operation approximately 3 years before admitted to the general surgery department in 2013 with complaint of palpable mass in the right breast which had a fast growing. There was no other remarkable feature in the patient's medical history. The mass was localized deeply without skin coloration change or signs of mastitis. She had no chronic illness or radiotherapy history and no family history of breast cancer. An excisional biopsy was performed on 07.06.2013 and revealed sarcomatous changes. The patient underwent a simple mastectomy after the frozen pathology was evaluated as angiosarcoma. Postoperative pathology revealed angiosarcoma, grade I, tumor diameter of $6 \times 5.5 \times 5 \mathrm{~cm}$, surgical margins $0.2 \mathrm{~cm}$ in the inferior, $2 \mathrm{~cm}$ in the posterior, continuation with the anterior skin, $5 \mathrm{~cm}$ in the medial and $9 \mathrm{~cm}$ in the superior surgical margin (Figures 1-4). There was no distant organ metastasis in the patient's positron emission tomography (PET)/computed tomography (CT).

Adjuvant radiotherapy was planned due to tumor size and continuation of tumor with the anterior skin. The patient was also evaluated by the medical oncology department and adjuvant chemotherapy was not considered. In July-August 2013, 50 Gray (Gy) (mean dose of 54 Gy) radiotherapy was applied in 25 fractions with 2 Gy dose per fraction to the chest wall of the patient with $0.5 \mathrm{~cm}$ bolus in the first 12 days by using 3-dimensional conformal radiotherapy technique (Figures 5, 6). 
Physical examination every 3 months and thoracic computed tomography every 6 months for the first 3 years and then once a year were performed during follow-up. Throughout the period of follow-up until February 2019, the patient had no evidence of local or distant metastasis. As the patient was living far away from the treatment center, follow-up procedures are evaluated by the photographs of the reports and informed consent is taken verbally by telephone before she sent it by post.

\section{Discussion and Conclusion}

PAS typically appears in women 30-50 years of age with no former history of cancer or recognizable risk factors. It composes less than

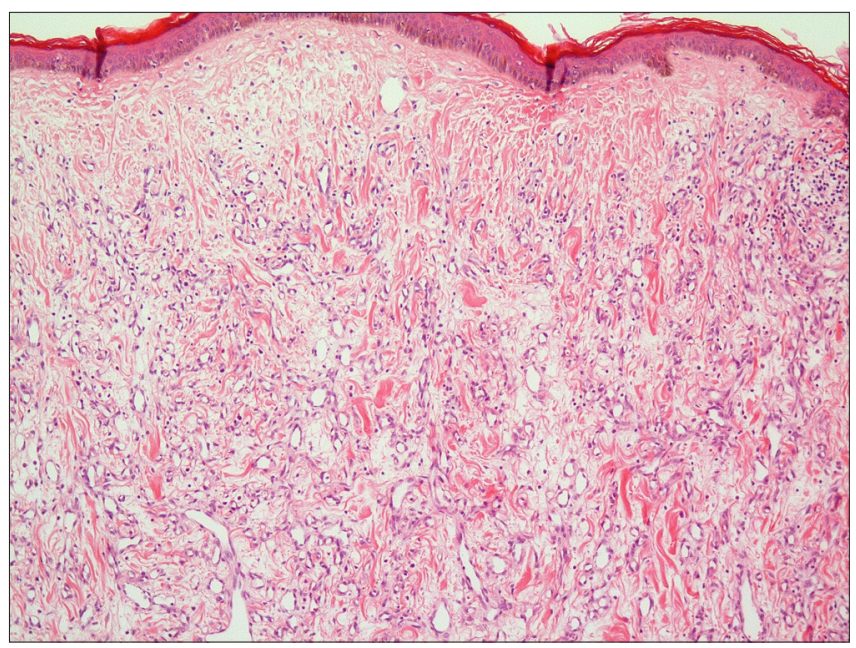

Figure 1. Increased number of vascular structures in subcutaneous tissue under breast skin (HEX100)

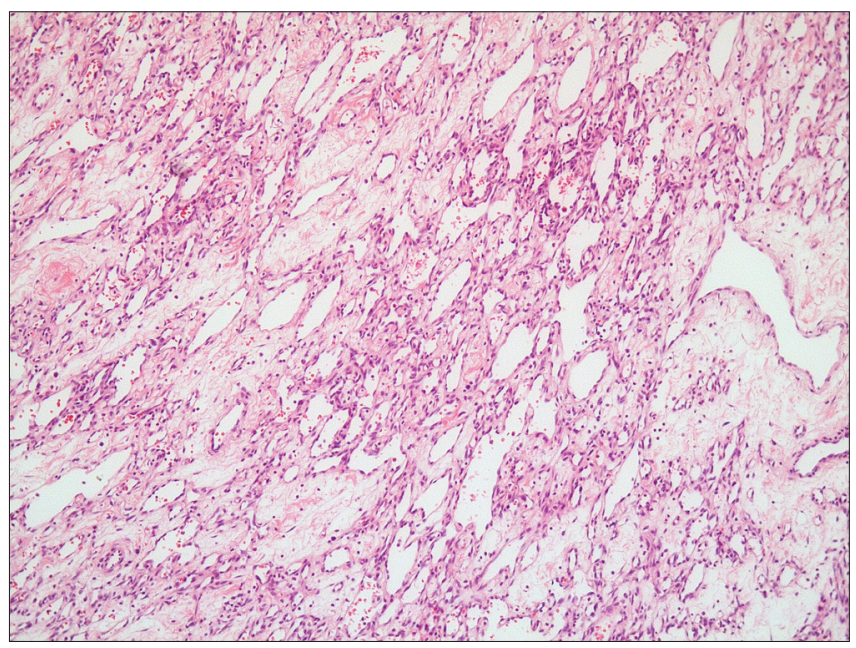

Figure 2. Infiltrative, anastomosed vascular channels in the deeper breast tissue (HEX100)

\section{Key Points}

- As primary angiosarcomas of the breast are very rare, it is not possible to use randomized trials to find out the standard treatment.

- The management of PAS must be carried by a multidisciplinary team.

- High risk PAS patients may survive long with aggressive treatments including adjuvant radiotherapy.
$0.04 \%$ of malignant tumors and typically appears in the parenchyma of the breast with uncommon skin involvement. Contrarily, secondary AS presents in elder women (median age 67-71 years) following a median of 10.5 years after radiotherapy for breast cancer. The median latent period to appearance after irradiation in seven series ranges from 5 to 10 years $(4)$.

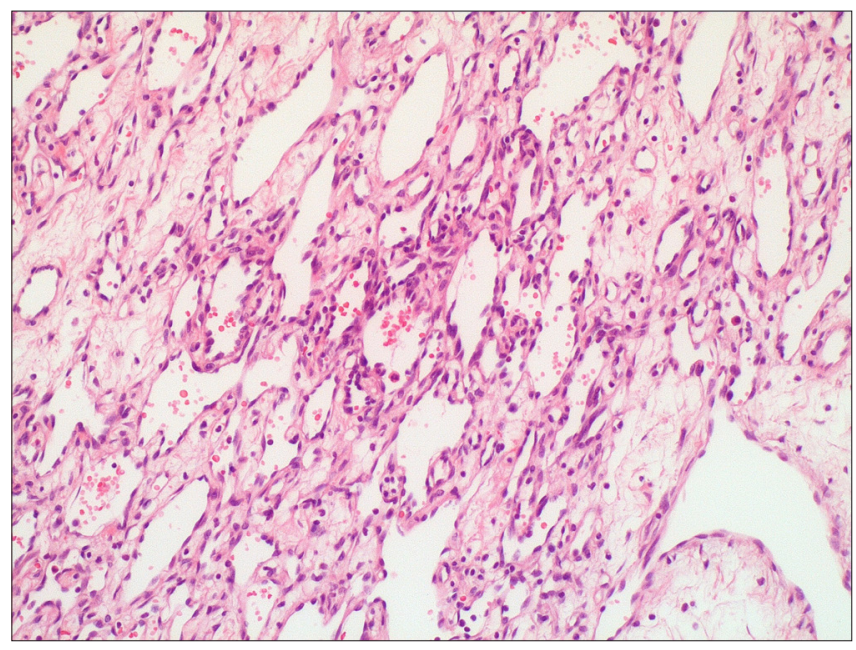

Figure 3. Spindle-like endothelial cells with prominent cytological atypia lining blood vessels (HEX200)

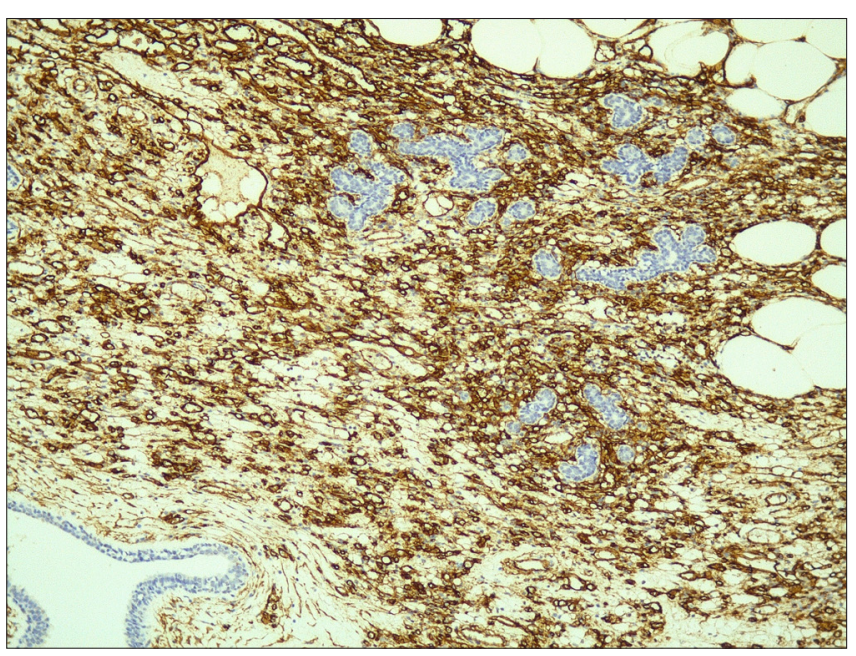

Figure 4. CD31 immunoreactivity in the tumor and intact ductus (lower left) and acinar structures (CD31X200)

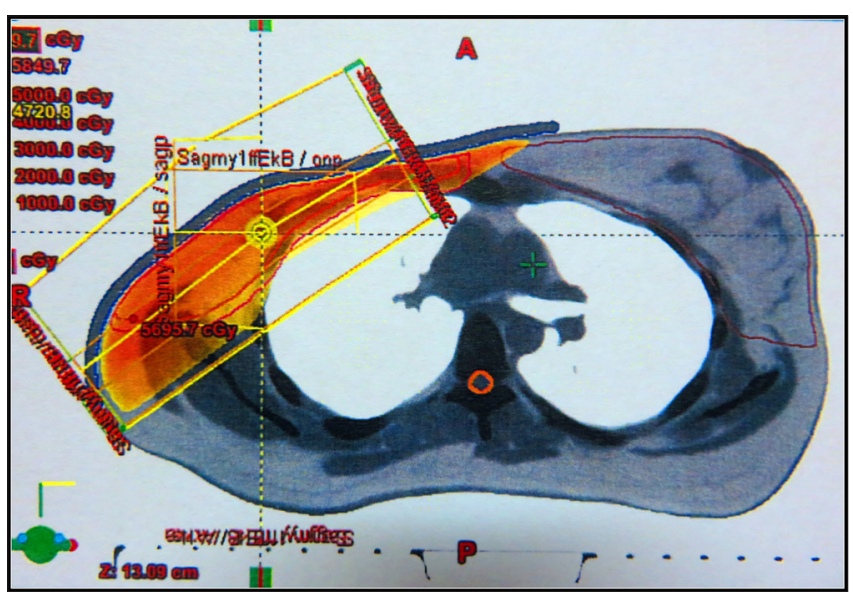

Figure 5. Isodose distribution of chest wall radiotherapy in axial slice 
Angiosarcoma may have a hidden clinical start, displaying frequently as a painless separate palpable mass that grows quickly. Nearly $2 \%$ of patients may exist with diffuse expansion of the breast. On the other hand, a bluish red discoloration of the overlying skin may be present (5). The age of our patient and the clinical symptoms of the disease were compatible with PAS.

Diagnosis may be difficult because of the absence of typical radiologic features on the mammogram or ultrasonogram. A Magnetic Resonance Imaging (MRI) of the breast is frequently helpful in specifying a tumor of vascular nature with malignant kinetic features. An exact preoperative diagnosis can be obtained with fine-needle aspiration cytology or a core needle biopsy (6). Chen et al. (7) declared that the false negative incidence of percutaneous biopsy was 37\%. Large-core biopsies might enable the accurate diagnosis as they ensure a larger sample, but such a macro biopsy is frequently hard to apply because of the vascular nature of these tumors. Surgical resection and microscopic examination of adequate sampling of the tumor are often necessary to give a final diagnosis which was the case for our patient (Figures 1 and 2) (5).

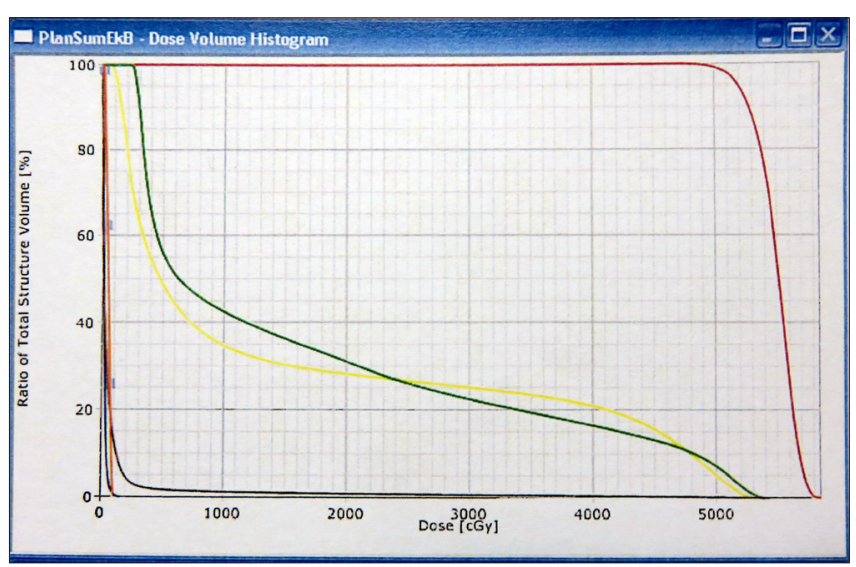

Figure 6. Dose-volume histogram (DVH) of radiotherapy plan
The histologic features of angiosarcoma of the breast are classified into grades I, II and III. In addition, immunohistochemistry can be useful to identify the clone JC/70A (CD31, the human hematopoietic progenitor cell antigen), endothelial indicator of vascular proliferation. Other specific markers for this kind of lesions are Factor VIII, and Friend leukemia integration 1 transcription factor (FLI1) (8). Angiogenesis, considered to be strongly affected by vascular endothelial growth factor (VEGF), is very important in the pathogenesis of these tumors. The histologic grade of primary angiosarcoma of the breast plays an important role in the estimation of outcomes, it is the most important prognostic indicator in cases of PAB (9). Concerning the correlation between high proliferation index and poor prognosis in a Grade II tumor in a study, Ozluk et al. (10) proposed that Ki-67 proliferation index should be used to predict nonhigh-grade tumors with unfavorable outcome. Low proliferation index of two grade I tumors in their study also supports the theory of relationship between Ki-67 antigen and aggressiveness of PAB.

Kaklamanos et al. (6) found that tumor size, grade, and margin status are the most important prognostic factors for survival. They remarked adjuvant multimodality therapy may improve the outcome in selected patients with breast angiosarcoma. Thirty-two PAS of the breast were reported by M.D. Anderson Cancer Center, 9 had received neoadjuvant or adjuvant radiotherapy combined with surgery and chemotherapy and overall survival of all was 59\%. Tumor recurrence was the only significant adverse prognostic factor for OS in multivariate analysis (11).

As angiosarcomas of the breast are very rare, there is no accepted standard treatment. Surgery (either mastectomy or wide excision) remains the basis of the treatment. Due to the highly aggressive course of the disease and its tendency to have local recurrence and distant metastasis, other treatment methods such as chemotherapy or radiotherapy should be used, under the inspection of a multidisciplinary team (3). The declared proportions of advanced/metastatic disease at presentation changes from 16 to $44 \%$, and the overall disease-specific survival

Table 1. Outcomes of primary breast angiosarcoma

\begin{tabular}{|c|c|c|c|c|}
\hline Author & Number of cases PAS/ Total & RT (+) & CT (+) & Outcome \\
\hline Kunkiel et al. (3) & $11 / 11$ & $5 / 11$ & $3 / 11$ & $\begin{array}{l}10 \text { patients }(91 \%) \text { relapsed with local or distant } \\
\text { recurrence. }\end{array}$ \\
\hline Vorburger et al. (11) & $32 / 55$ & $37 / 55$ & $9 / 32$ & $\begin{array}{l}\text { DFS and OS for all: median } 2.26 \text { and } 2.96 \text { years, } \\
\text { DFS and OS for PAS: } 3 \text {-year } 58 \% \text { and } 80 \%\end{array}$ \\
\hline Rosen et al. (12) & ?/63 (56 AS) & $15 / 63$ & $31 / 63$ & $\begin{array}{l}\text { 5-year OS: grade I 76\%, grade II 70\%, grade III } \\
15 \% .\end{array}$ \\
\hline Molitor et al. (16) & $8 / 8$ & $3 / 8$ & $0 / 8$ & Median DFS was 9 months, OS was 13 months \\
\hline Scow et al. (17) & $27 / 27$ & $11 / 27$ & $13 / 27$ & 5-year OS 46\% \\
\hline Sher et al. (18) & $56 / 69$ & $46 / 69$ & $30 / 69$ & $\begin{array}{l}\text { RFS and OS: median } 37 \text { and } 100 \text { months; } \\
\text { 5-year } 44 \% \text { and } 61 \% \text {; RT (-) / RT (+) 33\%/47\% and } \\
50 \% / 65 \%\end{array}$ \\
\hline Nacimento et al. (19) & $47 / 49$ & $12 / 49$ & $11 / 49$ & Median RFS was 2.1 years, OS was 5.8 years \\
\hline Luini et al. (20) & $9 / 16$ & $3 / 16$ & $5 / 16$ & DFS and OS for PAS: 5 -year $56 \%$ and $78 \%$ \\
\hline
\end{tabular}


is reported as roundly $30-40 \%$ in actual series (1). With respect to Rosen's study, the 5 years disease free survival rate for low grade tumors can be as high as $76 \%$ and up to $70 \%$ for intermediate grade tumors. However, 5 years survival rate for high grade tumors is about $15 \%$ (12).

Gross tumor resection with tumor negative resection margins is appraised as the preferred treatment whenever possible for localized disease. Nevertheless, some authors discuss that with the application of multimodal local treatment in scalp and face angiosarcomas, microscopically margin-negative resection, in which no gross or microscopic tumor remains in the primary tumor bed (R0 resection) does not give any advantage over complete tumor resection (debulking). This situation may be related with fewer complications and the tolerance of adjuvant therapies may be better (13). As local recurrence incidences are comparatively high even after R0 resection, adjuvant radiotherapy is generally suggested, and it has been correlated with better survival in some series $(14,15)$. Molitor et al. (16) published the outcome of 8 cases of primary breast angiosarcoma which were treated between 1954 and 1995. Only 3 had received adjuvant radiotherapy after mastectomy, median DFS and OS were 9 and 13 months consecutively. Scow et al. (17) reported twenty-seven cases of PAS of breast treated in Mayo Clinic. Median tumor size was $7.0 \mathrm{~cm}$ and $33 \%$ of tumors were high grade. All patients underwent mastectomy, eight of them received chemotherapy and radiotherapy, five patients received chemotherapy only, and three patients received radiation only. Five-year survival was $46 \%$.

Sher et al. (18) reported recurrence-free survival of $47 \%$ and $44 \%$ at 5 and 10 years in $68 \%$ of 69 patients irradiated compared with the patients who did not receive radiotherapy $(33 \%$ and $25 \%$ at 5 and 10 years respectively). This rate indicates that recurrence free survival is higher with adjuvant radiotherapy. When surgical resection is contraindicated or not possible, chemotherapy is taken into consideration with the aim of either palliation or downstaging the tumor to be suitable for resection. Even though there is no fixed standard systemic therapy, paclitaxel and doxorubicin are among the most active agents. Targeted therapies, especially new agents against angiogenesis are being explored (1).

In one retrospective analysis, Buehler et al. (1) reviewed demographic, tumor and treatment characteristics of 81 patients with angiosarcomas of different sites in the body (5/81 was PAS of breast) were evaluated at the University of Wisconsin Hospital and Clinic. By univariate analysis, significant unfavorable predictors of survival included metastases at presentation, visceral/deep soft tissue tumor location, tumor size $>5$ $\mathrm{cm}$, tumor necrosis and the lack of surgical excision. A tendency toward protracted survival was seen with radiation therapy and for chemotherapy in patients with metastases. A summary of the outcomes of primary breast angiosarcoma in the published literature is shown in Table $1(3,11,12,16-20)$.

Our patient with PAS is alive and disease-free for 66 months after mastectomy + adjuvant radiotherapy. Although tumor size was large and one surgical margin was tumor positive, the outcome is good because of the low grade and aggressive treatment. The management of PAS with multidisciplinary care, including plastic surgeons, medical, radiation and surgical oncologists is important to facilitate the complex decision making and to allow for the multimodality therapies necessary in the treatment of this aggressive malignancy.
Informed Consent: Written informed consent was obtained from patients who participated in this case.

Peer-review: Externally peer-reviewed.

Author Contributions: Concept - O.A., M.S., U.Y.; Design - O.A., M.S., U.Y.; Supervision - O.A., M.S.G., U.Y., M.N.A.; Resources - O.A., M.S.G., U.Y.; Materials - O.A., M.S.G., U.Y.; Data Collection and/or Processing O.A., M.S.G., U.Y.; Analysis and/or Interpretation - O.A., M.S.G., U.Y., M.N.A.; Literature Search - O.A., M.N.A.; Writing Manuscript - O.A., M.N.A.; Critical Review - O.A., M.S.G., U.Y., M.N.A.

Conflict of Interest: The authors have no conflicts of interest to declare.

Financial Disclosure: The authors declared that this study has received no financial support.

\section{References}

1. Buehler D, Rice SR, Moody JS, Rush P, Hafez GR, Attia S, Longley BJ, Kozak KR. Angiosarcoma outcomes and prognostic factors: a 25-year single institution experience. Am J Clin Oncol 2014; 37: 473-479. (PMID: 23428947) [CrossRef]

2. Fraga-Guedes C, Gobbi H, Mastropasqua MG, Botteri E, Luini A, Viale G. Primary and secondary angiosarcomas of the breast: a single institution experience. Breast Cancer Res Treat 2012; 132: 1081-1088. (PMID: 22207278) [CrossRef]

3. Kunkiel M, Maczkiewicz M, Jagiełło-Gruszfeld A, Nowecki Z. Primary angiosarcoma of the breast-series of 11 consecutive cases-a singlecentre experience. Curr Oncol 2018; 25: e50-e53. (PMID: 29507495) [CrossRef]

4. Arora TK, Terracina KP, Soong J, Idowu MO, Takabe K. Primary and secondary angiosarcoma of the breast. Gland Surg 2014; 3: 28-34. (PMID: 25083491)

5. Bhosale SJ, Kshirsagar AY, Patil MV, Wader JV, Nangare N, Patil PP. Primary angiosarcoma of breast: a case report. Int J Surg Case Rep 2013; 4: 362-364. (PMID: 23466684) [CrossRef]

6. Kaklamanos IG, Birbas K, Syrigos KN, Vlachodimitropoulos D, Goutas $\mathrm{N}$, Bonatsos G. Breast angiosarcoma that is not related to radiation exposure: a comprehensive review of the literature. Surg Today 2011; 41: 163-168. (PMID: 21264749) [CrossRef]

7. Chen KT, Kirkegaard DD, Bocian JJ. Angiosarcoma of the breast. Cancer 1980; 46: 368-371. (PMID: 7190060) [CrossRef]

8. Bordoni D, Bolletta E, Falco G, Cadenelli P, Rocco N, Tessone A, Guarino S, Accurso A, Amato B, Magalotti C. Primary angiosarcoma of the breast. Int J Surg Case Rep 2016; 20S: 12-15. (PMID: 26867719) [CrossRef]

9. Kim YS, Kim YJ, Yim KI, Park WC. A case report of primary breast angiosarcoma with fatal pulmonary hemorrhage due to thrombocytopenia. J Korean Surg Soc 2012; 82: 251-255. (PMID: 22493767) [CrossRef]

10. Ozluk Y, Tuzlalı S, Yavuz E, Derin D, Asoğlu O, İğci A, İlhan R, İplikçi A. Primary angiosarcoma of the breast: is KI-67 proliferation index related to histologic grade? does steroid hormone receptor expression play a role in the frequency of coexistent pregnancy? Eur J Breast Health 2006; 2: 127-130.

11. Vorburger SA, Xing Y, Hunt KK, Lakin GE, Benjamin RS, Feig BW, Pisters PWT, Ballo MT, Chen L, Trent 3rd J, Burgess M, Patel S, Pollock RE, Cormier JN. Angiosarcoma of the breast. Cancer 2005; 104: 26822688. (PMID: 16288486) [CrossRef]

12. Rosen PP, Kimmel M, Ernsberger D. Mammary angiosarcoma. The prognostic significance of tumor differentiation. Cancer 1988; 62: 21452151. (PMID: 3179927) [CrossRef]

13. Guadagnolo BA, Zagars GK, Araujo D, Ravi V, Shellenberger TD, Sturgis EM. Outcomes after definitive treatment for cutaneous angiosarcoma of the face and scalp. Head Neck 2011; 33: 661-667. (PMID: 20960566) [CrossRef] 
14. Mark RJ, Poen JC, Tran LM, Fu YS, Juillard GF. Angiosarcoma. A report of 67 patients and a review of the literature. Cancer 1996; 77: 2400-2406. (PMID: 8635113) [CrossRef]

15. Pawlik TM, Paulino AF, McGinn CJ, Baker LH, Cohen DS, Morris JS, Hunt KK, Hortobagyi GN, Gonzalez-Angulo AM. Cutaneous angiosarcoma of the scalp: a multidisciplinary approach. Cancer 2003; 98: 17161726. (PMID: 14534889) [CrossRef]

16. Molitor JL, Llombart A, Guinebretière JM, Zemoura L, Spielmann M, Contesso G, de Vathaire F, Zelek L, Kaylitalire L, Le Chevalier T, Genin $\mathrm{J}$. Angiosarcoma of the breast. Apropos of 8 cases and review of the literature. Bull Cancer 1997; 84: 206-211. (PMID: 9180846)

17. Scow JS, Reynolds CA, Degnim AC, Petersen IA, Jakub JW, Boughey JC. Primary and secondary angiosarcoma of the breast: the Mayo Clinic experience. J Surg Oncol 2010; 101: 401-407. (PMID: 20119983) [CrossRef]

18. Sher T, Hennessy BT, Valero V, Broglio K, Woodward WA, Trent J, Hunt KK, Hortobagyi GN, Gonzalez-Angulo AM. Primary angiosarcomas of the breast. Cancer 2007; 110: 173-178. (PMID: 17541936) [CrossRef]

19. Nascimento AF, Raut CP, Fletcher CD. Primary angiosarcoma of the breast: clinicopathologic analysis of 49 cases, suggesting that grade is not prognostic. Am J Surg Pathol 2008; 32: 1896-1904. (PMID: 18813119) [CrossRef]

20. Luini A, Gatti G, Diaz J, Botteri E, Oliveira E, Cecilio Sahium de Almeida R, Veronesi P, Intra M, Pagani G, Naninato P, Viale G. Angiosarcoma of the breast: the experience of the European Institute of Oncology and a review of the literature. Breast Cancer Res Treat 2007; 105: 81-85. (PMID: 17115110) [CrossRef] 